\title{
Effect of HSP90AB1 and CC Domain Interaction on Bcr-Abl Protein Cytoplasm Localization and Function in Chronic Myeloid Leukemia Cells
}

\section{Yuhang Peng}

Chongqing Medical University

\section{Zhenglan Huang}

Chongqing Medical University

\section{Fangzhu Zhou}

Chongqing Medical University

\section{Teng Wang}

Chongqing Medical University

\section{Ke Mou}

Chongqing Medical University

\section{wenli feng ( $\square$ fengwl@cqmu.edu.cn )}

Department of Clinical Hematology, Key Laboratory of Laboratory Medical Diagnostics Designated by Ministry of Education, School of Laboratory Medicine, Chongqing Medical University, Chongqing, China; https://orcid.org/0000-0002-0549-6223

\section{Research}

Keywords: chronic myeloid leukemia, nuclear localization, Bcr-Abl, HSP90AB1, coiled-coil domain

Posted Date: January 6th, 2021

DOl: https://doi.org/10.21203/rs.3.rs-139374/v1

License: (a) (1) This work is licensed under a Creative Commons Attribution 4.0 International License. Read Full License 


\section{Abstract}

Background: The fusion oncoprotein Bcr-Abl is mostly located in the cytoplasm, which causes chronic myeloid leukemia (CML). After moving into the nucleus, the fusion protein can induce apoptosis of CML cells. The coiled-coil domain (CC domain) of Bcr-Abl protein plays a central role in the subcellular localization. However, how CC domain affects subcellular localization of Bcr-Abl remains unclear.

Methods: Herein, the key proteins interacting with the Bcr-Abl CC domain were screened by immunoprecipitation binding mass spectrometry. The specific site of Bcr-Abl CC domain binding to target protein was predicted by Deep Viewer. Immunoprecipitation assay was used to confirmed the specific sites of protein binding. IF and western blot were used to observe the subcellular localization of target protein. Western blot was used to examine the protein changes. CCK-8, clonal formation test and FCM cycle detection were used to observe the effect of inhibitor on the proliferation ability of CML cells. FCM apoptosis detection was used to observe the level of cells apoptosis.

Results: HSP90AB1 interacts with Bcr-AbI CC domain via N-terminal domain (NTD), preventing the transport of Bcr-Abl protein to the nucleus and maintaining the activation of Bcr-Abl tyrosine kinase. The nucleus-entrapped Bcr-Abl markedly inhibits the proliferation and induces apoptosis of CML cells by activating p73 and repressing the expression of cytoplasmic oncogenic signaling pathways mediated by Bcr-Abl. Moreover, the combination of 17AAG (Tanespimycin) with Leptomycin B (LMB) considerably decreased the proliferation of CML cells.

Conclusion: Our study provides evidence that it is feasible to transport Bcr-Abl into the nucleus as an alternative strategy for the treatment of CML, and targeting the NTD of HSP90AB1 to inhibit the interaction with Bcr-Abl is more accurate for the development and application of HSP90 inhibitor in the treatment of CML and other Bcr-Abl-addicted malignancies.

\section{Plain English Summary}

The fusion oncoprotein Bcr-Abl is mostly located in the cytoplasm, which causes chronic myeloid leukemia (CML). After moving into the nucleus, the fusion protein can induce apoptosis of CML cells. The coiled-coil domain (CC domain) of Bcr-Abl protein plays a central role in the subcellular localization. In this study, we have demonstrated that the heat shock protein $90 \mathrm{kDa}$ alpha, class $\mathrm{B}$ member 1 (HSP90AB1) interacts with Bcr-Abl CC domain via N-terminal domain (NTD), preventing the transport of Bcr-Abl protein into the nucleus and therefore maintaining the activation of Bcr-Abl tyrosine kinase. This data suggests that 17AAG (Tanespimycin) antagonizes the NTD ATP function of HSP90AB1, prevents the formation of Bcr/Abl-HSP90AB1 complex and induces Bcr-Abl into the nucleus. These results demonstrated that nucleus-entrapped Bcr-Abl markedly inhibits the proliferation and induces apoptosis of CML cells by activating $\mathrm{p73}$ and repressing the expression of cytoplasmic oncogenic signaling pathways mediated by Bcr-Abl. Moreover, the combination of 17AAG with Leptomycin B (LMB) considerably decreased the proliferation of CML cells. In summary, our study provides evidence that it is feasible to 
transport Bcr-Abl into the nucleus as an alternative strategy for the treatment of $\mathrm{CML}$, and targeting the NTD of HSP90AB1 to inhibit the interaction with Bcr-Abl is more accurate for the development and application of HSP90 inhibitor in the treatment of CML and other Bcr-Abl-addicted malignancies.

\section{Background}

Chronic myeloid leukemia (CML) is a myeloid leukemia subtype represented by the formation of Bcr-Abl fusion gene [1, 2]. This fusion gene plays a critical role in CML pathology, encoding Bcr-Abl oncoprotein which accommodates tyrosine kinase activity that can activate multiple downstream signal targets involved in the regulation of cell malignant proliferation and apoptosis, including JAK-STAT [3, 4], RASMAPK[5] and CRKL[6, 7]. Imatinib, the first-line tyrosine kinase inhibitor (TKI) (IM), dasatinib and nilotinib, the second-generation kinase inhibitors are remarkably effective treatments for patients in chronic phase [8-11]. However, the occurrence of drug resistance or disease relapse urgently need the development of alternative treatments $[12,13]$.

Bcr-Abl oncoprotein primarily localized in the cytoplasm. It has the same effector domain as c-Abl whereas c-Abl shuttles between the cytoplasm and nucleus[14]. Based on our previous work, we have designed a drug transduction system to direct the oncogenic Bcr-Abl into the nucleus and induce the apoptosis of CML cells by tyrosine kinase activity[15]. Similar studies also have shown that Bcr-Abl induces the apoptosis of CML cells when transported into the nucleus[16-18]. Notably, the localization of Bcr-Abl plays a crucial role in the development of CML disease, and the coiled-coil domain (CC domain) at the $\mathrm{N}$-terminal of Bcr-Abl is a major determinant for the location in the cytoplasm[19, 20]. We had constructed the pAdTrack-Bcr/Abl- $\triangle \mathrm{CC}$ expression vector which successfully induces Bcr-Abl transportation into the nucleus after its transfection into 293T cells (Supplementary Fig. 1). However, how CC domain affects subcellular localization of Bcr-Abl remains unclear.

As one of the molecular chaperones, Heat Shock Protein 90 (HSP90) functions to facilitate the correct folding of synthesized and denatured oncogenic proteins that participate in leukemia, including Bcr-Abl and its downstream signaling partners[21-23]. Therefore, the dependence on HSP90 has promoted the anti-leukemia drug development by depleting the molecular chaperone and degrading oncogenic Bcr-Abl, therefore eliciting apoptosis of leukemia cells[24-26]. Previous studies have shown that inhibition of the $\mathrm{N}$ - and $\mathrm{C}$-terminal termini can disrupt HSP90 chaperone function and cause the degradation of Bcr-Abl oncoprotein. Both 17-AAG, the N-terminal inhibitor and cisplatin, the C-terminal inhibitor have the capacity to suppress progenitor cells and deplete the leukemia stem cells[27-29]. However, the role of HSP90, which affects the subcellular localization of Bcr-Abl, has not been reported.

HSP90AB1, also recognized as HSP90 beta, is a member of the HSP90 family which includes HSP90 alpha (HSP90AA1) and HSP90 beta. HSP90 proteins play an important role in cell regulation, forming complexes with various transcription factors, cellular kinases, and some molecules[30-32]. In this study, we have discovered the effect of the interaction between HSP90AB1 and the CC domain on Bcr-Abl cytoplasm localization and its function in chronic myeloid leukemia cells. After confirming the binding of 
CC domain with HSP90AB1, we explored the specific binding sites of HSP90AB1 with Bcr-Abl. Further studies have suggested that Bcr-Abl enters the nucleus after destruction of the HSP90AB1-Bcr/Abl complex. The activation of downstream signaling molecule of Bcr-Abl was downregulated. Similarly, the nucleus-entrapped Bcr-Abl causes the activation of p73 and its downstream signaling molecules, markedly inducing the apoptosis and inhibiting the proliferation of CML cells. In our study, we explored the interaction between CC domain and HSP90AB1, and Bcr-Abl was translocated into the nucleus after dissociation with HSP90AB1. Moreover, we elucidated the mechanism of apoptosis induced by the HSP90 inhibitor after Bcr-Abl was translocated into the nucleus. Our study also found the effect of targeted killing of CML cells is enhanced under the action of 17AAG and LMB inhibitors.

\section{Materials And Methods \\ Cell lines and cell culture}

K562 (Cell Bank of Shanghai Institute of Cell Biology, Chinese Academy of Sciences) and K562/G01 cell lines were grown and maintained in RPMI-1640 medium supplemented with 10\% fetal bovine serum (Gibco, USA). K562/G01 is an imatinib-resistant cell line obtained from K562 treated for several months with persistently increased concentration of imatinib up to $5 \mathrm{mg} / \mathrm{L}$. $293 \mathrm{~T}$ cells were grown and maintained in Dulbecco's modified Eagle medium (DMEM) containing $10 \%$ fetal bovine serum. All of these cells were maintained in a humidified atmosphere with $5 \% \mathrm{CO} 2$ at $37^{\circ} \mathrm{C}$.

\section{Identification of CC domain-interacting partners}

293T cells stably expressing HA-tagged Bcr-Abl were lysed for 30 minutes and subjected to centrifugation at $12,000 \mathrm{~g}$ for 30 minutes. The collected supernatant was incubated overnight at $4^{\circ} \mathrm{C}$ with Protein $\mathrm{A} / \mathrm{G}$ magnetic beads adsorbed with anti-HA epitopes antibody (Cell Signaling Technology).

Immunoprecipitation proteins adsorbed on magnetic beads were eluted for western blot assay, and the location of CC-domain specific interacting proteins on SDS-PAGE gel was found by silver staining. The target strip was cut and the specific proteins were identified by the Protein Facility at the Center of Biomedical Analysis.

\section{Co-immunoprecipitation (Co-IP) and immunoblot analysis}

Protein A/G magnetic beads were washed three times with TBST and then incubated with HA-tagged or DYKDDDDK-tagged antibody (Cell Signaling Technology) at room temperature for $1 \mathrm{hr}$. Protein lysates extracted from 293T cells were added to Protein A/G magnetic beads and incubated overnight at $4{ }^{\circ} \mathrm{C}$. The immunoprecipitation proteins adsorbed on the magnetic beads were eluted for western blot assay, and the interaction between HSP90AB1 protein and the CC domain was observed by western blot.

\section{Western blotting}

Western blotting assay was performed as previously described[15]. We purchased the following antibodies from Cell Signaling Technology of USA: c-ABL(\#2862), Phospho-c/ABL(\#2864), HA- 
Tag(\#3724), DYKDDDDK-Tag(\#8146), PARP(\#9532), Caspase-3(\#9662), BID(\#2002), PhosphoAKT(\#9271), AKT(\#9272), Phospho-STAT5(\#9351), p73(\#14620), and p21(\#2947S). The HSP90-beta antibody (Genetex, \#101448 USA) and $\beta$-actin antibody (BOSTER, bs-0061R China) were the same as the antibodies used above with 1:1000 dilution.

\section{Transfection}

The plasmid of $\mathrm{pAdTrack-Bcr/Abl}$ and $\mathrm{pAdTrack}-\mathrm{Bcr} / \mathrm{Abl}-\triangle \mathrm{CC}$ was maintained in our laboratory. The pAdTrack-HSP90AB1 and pAdTrack-HSP90AB1- $\triangle$ NTD expression plasmid purchased from Addgene. Cells were transfected with the plasmid of HSP90AB1, and BCR-ABL with Lipofactamine2000 (Invitrogen, Carlsbad, CA, USA), according to the protocol. All constructs were verified through DNA sequencing and western blot analysis.

\section{Immunofluorescence assay}

Cells were collected for immunofluorescence assay, washed 3 times by PBS and then coated on slides, fixed (30 min, 4\% paraformaldehyde solution), permeabilized (20 min, 0.1\% Triton X-100), blocked ( $2 \mathrm{hrs,}$ goat serum) and then incubated with primary antibodies (1:500 in goat serum). After incubation with a fluorescent-labeled secondary antibody (Introvigen, USA) in darkness for $1 \mathrm{hr}$ at $37^{\circ} \mathrm{C}$, cells were stained with diluted DAPI (15 min, 1:1000 in PBS).

\section{CCK-8 assay}

$\mathrm{CML}$ cells in the logarithmic growth phase were taken and added to the 96-well culture plate at a density of 4000 cells per well with $100 \mu \mathrm{l}$ RPMI 1640 containing $15 \%$ fetal bovine serum and cultured at $37^{\circ} \mathrm{C}$ in a 5\% CO2 humidified incubator. Each well was added with $10 \mu \mathrm{l} \mathrm{CCK-8} \mathrm{(MCE,} \mathrm{USA)} \mathrm{at} \mathrm{the} \mathrm{indicated} \mathrm{time}$ and incubated for $1 \mathrm{hr}$ at $37^{\circ} \mathrm{C}$ in darkness. The absorbance at $450 \mathrm{~nm}$ was measured on a microplate. Each group included four counterparts and was performed three times.

\section{Cell Colony-forming assay}

K562 and K562/G01 cells were taken and added to the 24-well culture plate at a density of 500 cells per well mixed with RPMI 1640 medium containing $20 \%$ serum to form a cell suspension of $750 \mathrm{~L} ; 750 \mathrm{~L} 1.8 \%$ methylcellulose (Sigma, USA) was added in and thoroughly mixed, with 3 parallel holes in each group. The colony number was observed and counted after being cultured at $37^{\circ} \mathrm{C}$ for $10 \mathrm{~d}$ in a $5 \% \mathrm{CO} 2$ incubator. The colony formation assay was performed five times.

\section{Apoptotic and Cell Cycle Analysis}

K562 and K562/G01 cells, after being treated with 17AAG, LMB and IM at the indicated concentration, were collected and added into 6-well culture plate at a density of $1 \times 10^{6}$ cells per well. Apoptosis was assessed using an Apoptosis Detection Kit according to the instruction. Moreover, nuclear morphology was examined by DAPI staining, and the results were observed with the fluorescence microscope. The cell cycle was analyzed by PI staining, and quantified by using FCM. The percentage of cells in different phases of the cell cycle was determined and quantitated. 


\section{Statistical methods}

All statistical results were shown as mean \pm SD. The statistical significance among each group was assessed by one-way ANOVA analysis. Statistical analyses were calculated with GraphPad Prism 5.0 software. Results with statistical significance were marked with asterisks. Statistical significance is indicated as $p<0.05$.

\section{Results}

\section{Identification of HSP90AB1 as a Bcr/Abl binding partner}

In eukaryotic cells, the interaction between proteins affects the subcellular localization of proteins. We hypothesized that certain proteins in the cytoplasm that bind to the CC domain for anchoring the Bcr-Abl protein in the cytoplasm. To identify the potential partners of Bcr-Abl, firstly, we used 293T cells expressing HA-tagged Bcr/Abl and HA-tagged Bcr/Abl- $\triangle \mathrm{CC}$. The location of CC-domain specific interacting proteins on SDS-PAGE gel was found by silver staining (Fig. 1A). The target strip was cut, and the specific proteins were identified by the protein facility, which led to the identification of HSP90AB1 as a differential protein related to protein subcellular localization and associated with the CC domain of BcrAbl (Fig. 1B; Fig. 1C).

\section{Association between the Bcr/Abl CC-domain and $\mathrm{N}$-terminal domain of HSP90AB1}

To confirm the intracellular binding of HSP90AB1 and CC domain, we enforced the expression of HA$\mathrm{Bcr} / \mathrm{Abl}$ and DYK-HSP90AB1 in 293T cells for reciprocal immunoprecipitation and confirmed the associations between HSP90AB1 and Bcr-Abl proteins (Fig. 2A). To further explore the specific binding sites of HSP90AB1-Bcr/Abl interaction, we have simulated the three-dimensional structure diagram of the binding protein Bcr/Abl-HSP90AB1, in which the N-terminal region of HSP90AB1 (amino acids 1-693) was predicted to bind to Bcr-Abl (Fig. 2B). To assess the importance of the $\mathrm{N}$-terminal region in mediating Bcr/Abl-HSP90AB1 interaction, we synthesized the DYK-tagged HSP90AB1- $\triangle$ NTD expression plasmid (amino acids 694-2176 of HSP90AB1) and DYK-tagged HSP90AB1 expression plasmid to test their reciprocal interaction with Bcr-Abl (Supplementary Fig. 2; Fig. 2C). The transfection efficiency of the target vector in 293T cells was observed by immunofluorescence, as we transfected DYK-pAdTrack-HSP90AB1 and DYK-pAdTrack-HSP90AB1- $\triangle$ NTD with HA-pAdTrack-Bcr/Abl into 293T cells (Fig. 2D). As expected, the DYK-HSP90AB1 but not the DYK-HSP90AB1- $\triangle$ NTD efficiently pulled down Bcr-Abl in HA-tagged BcrAbl group, meanwhile, the HA-tagged Bcr-Abl efficiently pulled down DYK-HSP90AB1 (Fig. 2E; Fig. 2F). In a nutshell, those results provide evidence supporting that HSP90AB1 is a direct Bcr/Abl-binding partner, and the N-terminal region of HSP90AB1 (amino acids 1-693) is responsible for the interaction between BcrAbl and HSP90AB1. 


\section{Inhibition of HSP90AB1 induces nuclear localization of $\mathrm{Bcr} / \mathrm{Abl}$ in $\mathrm{CML}$ cells}

17AAG (Tanespimycin) is a classic HSP90 specific N-terminal inhibitors that inhibits the chaperone function of HSP90 and dissociates it from the chaperone protein. Here, we hypothesized that HSP90AB1 may regulate the localization of Bcr-Abl. To test this hypothesis, we have observed the changes of Bcr-Abl in its subcellular localization after dissociation with HSP90AB1, and after the use of the appropriate concentration of 17AAG (Fig. 3A; Fig. 3B).

The Bcr-Abl protein has three complete nuclear localization signals and a nuclear output signal, so it can shuttle between the cytoplasm and nucleus[33]. Considering the part of Bcr-Abl was transported out of the nucleus after entering the nucleus, we added protein nucleus output inhibitor LMB (Leptomycin) and HSP90 inhibitor 17AAG to treat K562 cells and observed the changes of Bcr-Abl in its subcellular localization. As shown in Fig. 3C, Bcr-Abl was scattered in the cytoplasm without nucleation in the control group, and there was a co-localization relationship between HSP90AB1 and Bcr-Abl as a molecular chaperone in the cytoplasm. Bcr-Abl showed significant nuclear localization after treatment with 17AAG. This increase in nuclear Bcr-Abl was enhanced by the treatment with 17AAG and LMB. Next, we investigated the subcellular localization of Bcr-Abl by extracting proteins from the cytoplasm and the nucleus and by performing western blot analyses. The expression of Bcr-Abl in the nuclear increased in concentration dependence, with the increasing concentration of HSP90 inhibitor (Fig. 3D; Fig. 3E). The inhibition of HSP90 chaperone function had a significant effect on the subcellular localization of Bcr-Abl, and the formation of HSP90AB1-Bcr/Abl complex also led to the localization of Bcr-Abl protein in the cytoplasm.

\section{Nuclear transport of Bcr/Abl induced apoptosis in K562 and K562/G01 cells through Bcr/Abl kinase- dependent and Bcr/Abl-independent pathways}

To examine the effect of Bcr-Abl on CML cells after nucleation, we used immunofluorescence assay to observe the changes of the nuclear morphological structure of K562 cells treated with HSP90 inhibitor 17AAG for $6 \mathrm{hrs}$ and $12 \mathrm{hrs}$ (Fig. 4A). Some of the nucleus deformed after treatment for $6 \mathrm{hrs}$, and some cells showed nuclear fragmentation after treatment for $12 \mathrm{hrs}$, suggesting the occur of CML cell apoptosis. Then, we investigated the activation of apoptosis-related proteins in K562 and K562/G01 cells after treatment with 17AAG by using western blot analyses. BID, a bcl-2 family protein, is generated by the hydrolysis of caspase-8 in the Fas signaling pathway and can play a pro-apoptotic role. As predicted, the expression of BID protein increased in a concentration dependent manner in K562 and K562/G01 cells. Cleaved poly ADP-ribose polymerase (PARP) and caspase-3 are also cut into segments during apoptosis, which is also a typical feature of apoptosis (Fig. 4B; Fig. 4C). It was suggested that Bcr-Abl play a role in promoting apoptosis after entering the nucleus. Next, we observed the changes in activation of Bcr-Abl and its downstream signaling molecules in K562 and K562/G01 cells after Bcr-Abl was induced into the nucleus (Fig. 4D). The expression of Bcr-Abl, p-Bcr-Abl and downstream signaling molecules p-AKT, pSTAT5 in K562 cells decreased in a concentration-dependent manner with the increase of inhibitor 
concentration, which suggested that the expression of downstream signaling molecules of Bcr-Abl was down-regulated, and the malignant proliferation of CML cells was inhibited. Our previous research has reported that nuclear localization of c-Abl causes activation of p73 and induces cell apoptosis[15, 18, 34]. To confirm that Bcr-Abl located in the nucleus plays the same effects on $\mathrm{p73}$ in CML cells, we examined the expression of p73 and its downstream targets. As expected, we found that the level of p73 protein was increased by 17AAG treatment, and the expression of p21 and PUMA was also significantly enhanced (Fig. 4E). These results demonstrated that Bcr-Abl located in the nucleus can inhibit the proliferation and induce the apoptosis of CML cells through activating p73 and down-regulating the expression of Bcr-Abl downstream oncogenic proteins.

\section{Combination of 17AAG and LMB significantly enhances the anti-leukemia effect in vitro}

Previous data showed that HSP90 inhibitors can induce Bcr-Abl transportation into the nucleus and promote the apoptosis of CML cells, and the inhibitor of protein nuclear export $\mathrm{LMB}$ can prevent the transport of Bcr-Abl out of the nucleus. Therefore, it was speculated that the killing ability could be enhanced with the two inhibitors combined targeting CML cells. The results of the proliferation assay showed that 17AAG could significantly inhibit the malignant proliferation of CML cells, and the CML cell apoptosis was more highly promoted in the drug combination group (Fig. 5A; Fig. 5B). The result of colony formation was the same as the proliferation assay. Compared with the group of 17AAG or IM treatment, 17AAG with LMB treatment significantly reduced the proliferation of K562 and K562/G01 cells (Fig. 5C; Fig. 5D). Next, we used flow cytometry analyzer to detect cell cycle and apoptosis, in order to further confirm that HSP90 inhibitor 17AAG combined with protein nucleocapsid inhibitor LMB can enhance the killing ability when targeting CML cells. Cell cycle results showed that compared with other groups, more cells in the drug combination group were blocked in G1-2 phase before DNA replication, with relatively fewer cells in $\mathrm{S}$ phase, suggesting that the malignant proliferation capacity of $\mathrm{CML}$ cells was significantly reduced with the drug combination treatment (Fig. 6A; Fig. 6B). Apoptosis data showed that a larger proportion of CML cells in the combined group have been induced to apoptosis, and the two drugs combined could enhance the ability of promoting apoptosis of CML cells (Fig. 6C; Fig. 6D).

We have observed the effect of drug combination treatment on the activation of Bcr-Abl and downstream signaling molecules in K562 and K562/G01 cells. Compared with the 17AAG inhibitor and IM treatment alone, the drug combination treatment significantly down-regulated the expression of Bcr-Abl and downstream signaling molecules p-STAT5 and p-AKT (Fig. 5E). The above experiment results indicated that HSP90 inhibitor 17AAG combined with the inhibitor of protein nucleus export LMB could enhance the killing ability when targeting CML cells. And the expression of Bcr-Abl and the downstream signaling molecules are more significantly down-regulated when 17AAG was used in combination with the LMB.

\section{Discussion}


The first line treatment of chronic myeloid leukemia patients is the TKIs, which are applied in clinical treatment with satisfactory efficacy and minor side effects[35]. Nonetheless, CML cells develop TKIs resistance because of the mutations of Bcr-Abl kinase region and pathogenicity of leukemia stem cells. Furthermore, TKIs have inconspicuous effect on some patients who transitioned from the chronic phase to the acute phase[36]. Therefore, identification of novel drug targets needed for CML treatment.

Many progresses have been made in identifying downstream signaling molecules activated by Bcr-Abl during $C M L$ pathogenesis $[4,6,37]$. Yet not much is known about the molecular mechanisms sustaining Bcr-Abl localization in the cytoplasm, especially those critical for the development of CML. The localization of Bcr-Abl is an important determinator the development of CML disease, and the CC domain of Bcr-Abl mainly affects its location in the cytoplasm[19, 20]. Protein interactions in leukemia cells can affect protein subcellular localization, hence we speculated that certain proteins in the cytoplasm may bind to the CC domain to retain Bcr-Abl in the cytoplasm[38]. In this study, we screened the target protein HSP90AB1 which is over-expressed in a large variety of cancer cells and belongs to highly conserved ATP-dependent molecular chaperone. HSP90AB1 interacts with transcription factors, cellular kinases, and various molecules to participate in lots of pathophysiological processes of cells[39]. However, the role of HSP90AB1 in the pathogenesis of leukemia is rarely reported. In this report, we have found that HSP90AB1 interacts with the CC domain of Bcr-Abl in the cytoplasm to prevent its degradation. Finding the specific binding site can help us target the Bcr/Abl-HSP90AB1 complex for dissociation. So, we modeled a three-dimensional structure diagram of the Bcr/Abl-HSP90AB1 complex. The direct interaction between the CC domain and the NTD of HSP90AB1 was determined by co-immunoprecipitation. At present, the development and application of HSP90 inhibitors have become a hotspot in tumor therapy, and the targets of inhibitors are also various[25]. The exploration of specific site can make the HSP90 inhibitor more accurate in the selection of therapeutic targets for CML and other Bcr-Abl-addicted disease.

The specific localization of Bcr-Abl in the cytoplasm can cause malignant transformation of blood cells, whereas Bcr-Abl induces the apoptosis of CML cells after transporting into the nucleus[15]. In this study, we found the decisive cause for the retention of Bcr-Abl in cytoplasm is the formation of Bcr/AblHSP90AB1 complex. For the previously identified binding site, we selected the 17AAG inhibitor that can promote HSP90AB1 dissociation with chaperone protein by antagonizing the NTD ATP function[40]. Interestingly, the Bcr-Abl is transported into the nucleus from the cytoplasm when dissociated with HSP90AB1 under the treatment of 17AAG. The nuclear Bcr-Abl down-regulates the cytoplasmic proliferation signaling activated by the tyrosine kinase of cytoplasmic Bcr-Abl. At the same time, the nuclear Bcr-Abl induces p73 and its downstream targets through c-Abl kinase (Fig. 7). The above experiment results illustrate that the Bcr-Abl can be directed into the nucleus, and Bcr-Abl located in nucleus can induce apoptosis and inhibit the proliferation of CML cells by DNA damage and inhibition of the tyrosine kinase activity. Our research in the early stage conducted a series of studies on the localization of Bcr-Abl, which confirmed its significance to CML. The exploration of the mechanism of specific localization of Bcr-Abl lays the foundation for further study on the pathogenic effect of Bcr-Abl in CML. Furthermore, these data describe a previously neglected strategies, promote the apoptosis of CML cells by inducing the transport of Bcr-Abl into the nucleus. 
Targeting protein subcellular localization is considered challenging, because the protein may be transported out of the nucleus after being induced into the nucleus[41]. The Bcr-Abl and c-Abl have similar structural sites, both containing three nuclear localization signals and a nuclear output signal, so it can shuttle between the cytoplasm and nucleus, but is mainly located in the cytoplasm. Considering the nuclear shuttle function of Bcr-Abl, we used the protein nuclear export inhibitor Leptomycin B (LMB)[17]. Our immunofluorescence results displayed that using LMB alone does not affect the localization of Bcr$\mathrm{Abl}$, but can transport Bcr-Abl into the nucleus in combination with 17AAG. Based on the above results, we then clearly indicated that targeting chronic myeloid leukemia cells, the combination of the two inhibitors can enhance the killing ability. Malignant leukemia cells are particularly sensitive to HSP90 inhibition, leading to the steady development of clinical HSP90 inhibitors[42, 43]. Recently, there are more than thirty positive clinical trials involving the use of HSP90 inhibitors[44, 45]. Conceivably, HSP90 inhibitors will be used as potential alternative therapies to benefit CML patients with Imatinib resistance. However, most current studies on HSP90 inhibitors for the treatment of leukemia have focused on the functional structure of HSP90 and its effect on the phosphorylation or tyrosine kinase activity of the chaperone protein[25, 29, 46]. Following the previous results, our study focuses on the effects of HSP90AB1 on the localization and function of Bcr-Abl, and our findings provide an innovative strategy to develop new therapy of CML. The identification of interaction site in this study can help the development of new HSP90 inhibitors to find the effectively targets[46].

\section{Conclusions}

In summary, we have confirmed that HSP90AB1 plays a critical role in the subcellular localization of Bcr$\mathrm{Abl}$, which directly affects the development and progression of CML. Based on it, we used both 17AAG and LMB inhibitors to induce Bcr-Abl to be transported into the nucleus. Our data suggest that the combined action of the two inhibitors can enhance the killing ability when targeting CML cells. By finding the important interaction sites between Bcr-Abl and HSP90AB1, our study provides the basis for clinical development of HSP90 inhibitors in treating CML and other Bcr-Abl-addicted malignancies.

\section{Abbreviations}

Ad

Adenovirus; BCR:Break cluster region; BSA:Bovine serum albumin; CML:chronic myeloid leukemia; CC domain:The coiled-coil domain; Co-IP:Co-immunoprecipitation; CCK-8:Cell Counting Kit-8; HSP90AB1:heat shock protein 90 kDa alpha, class B member 1; IM:imatinib; LMB:Leptomycin B; NTD:N-terminal domain; NLS:nuclear localization signal; NES:nuclear export signal; PCR:Polymerase chain reaction; TKI:tyrosine kinase inhibitor; 17AAG:17-allylamino-17-demethoxygeldanamycinin.

\section{Declarations}

Acknowledgements 
The authors thank Professor Zhan Yang for his generous help in the grammar correction.

\section{Authors' contributions}

YP, ZH and WF initiated the work and designed the experiments. YP performed the experiments and wrote the manuscript. FZ and $\mathrm{KM}$ were responsible for the literature search. $\mathrm{ZH}$ and TW contributed to data curation. All the authors read and approved the final manuscript.

\section{Funding}

This work was supported by National Natural Science Foundation of China (No.81572060 to Wenli Feng).

\section{Availability of data and materials}

The datasets supporting the conclusions of this article are included within the article and its additional files.

\section{Ethics approval and consent to participate}

Not applicable.

\section{Consent for publication}

All authors consent to publication.

\section{Competing interests}

The authors have declared that no competing interest exists.

\section{References}

1. Quintas-Cardama A, Cortes J: Molecular biology of bcr-abl1-positive chronic myeloid leukemia. Blood 2009, 113(8):1619-1630.

2. Rowley JD: Letter: A new consistent chromosomal abnormality in chronic myelogenous leukaemia identified by quinacrine fluorescence and Giemsa staining. Nature 1973, 243(5405):290-293.

3. Ren R: Mechanisms of BCR-ABL in the pathogenesis of chronic myelogenous leukaemia. Nat Rev Cancer 2005, 5(3):172-183.

4. Steelman LS, Pohnert SC, Shelton JG, Franklin RA, Bertrand FE, McCubrey JA: JAK/STAT, Raf/MEK/ERK, PI3K/Akt and BCR-ABL in cell cycle progression and leukemogenesis. Leukemia 2004, 18(2):189-218.

5. Asmussen J, Lasater EA, Tajon C, Oses-Prieto J, Jun YW, Taylor BS, Burlingame A, Craik CS, Shah NP: MEK-dependent negative feedback underlies BCR-ABL-mediated oncogene addiction. Cancer Discov 2014, 4(2):200-215. 
6. Hazlehurst LA, Bewry NN, Nair RR, Pinilla-lbarz J: Signaling networks associated with BCR-ABLdependent transformation. Cancer Control 2009, 16(2):100-107.

7. Oda A, Miyakawa Y, Druker BJ, Ishida A, Ozaki K, Ohashi H, Wakui M, Handa M, Watanabe K, Okamoto $\mathrm{S}$ et al: Crkl is constitutively tyrosine phosphorylated in platelets from chronic myelogenous leukemia patients and inducibly phosphorylated in normal platelets stimulated by thrombopoietin. Blood 1996, 88(11):4304-4313.

8. Castagnetti F, Gugliotta G, Breccia M, lurlo A, Levato L, Albano F, Vigneri P, Abruzzese E, Rossi G, Rupoli S et al: The BCR-ABL1 transcript type influences response and outcome in Philadelphia chromosome-positive chronic myeloid leukemia patients treated frontline with imatinib. Am J Hematol 2017, 92(8):797-805.

9. Hochhaus A, Saglio G, Larson RA, Kim DW, Etienne G, Rosti G, De Souza C, Kurokawa M, Kalaycio $M E$, Hoenekopp A et al: Nilotinib is associated with a reduced incidence of BCR-ABL mutations vs imatinib in patients with newly diagnosed chronic myeloid leukemia in chronic phase. Blood 2013, 121(18):3703-3708.

10. Steegmann JL, Baccarani M, Breccia M, Casado LF, Garcia-Gutierrez V, Hochhaus A, Kim DW, Kim TD, Khoury HJ, Le Coutre $P$ et al: European LeukemiaNet recommendations for the management and avoidance of adverse events of treatment in chronic myeloid leukaemia. Leukemia 2016, 30(8):16481671.

11. O'Hare T, Zabriskie MS, Eiring AM, Deininger MW: Pushing the limits of targeted therapy in chronic myeloid leukaemia. Nat Rev Cancer 2012, 12(8):513-526.

12. Efficace F, Baccarani M, Breccia M, Alimena G, Rosti G, Cottone F, Deliliers GL, Barate C, Rossi AR, Fioritoni $\mathrm{G}$ et al: Health-related quality of life in chronic myeloid leukemia patients receiving long-term therapy with imatinib compared with the general population. Blood 2011, 118(17):4554-4560.

13. Gorre ME, Mohammed M, Ellwood K, Hsu N, Paquette R, Rao PN, Sawyers CL: Clinical resistance to STI-571 cancer therapy caused by BCR-ABL gene mutation or amplification. Science 2001, 293(5531):876-880.

14. Hantschel O, Superti-Furga G: Regulation of the c-Abl and Bcr-Abl tyrosine kinases. Nat Rev Mol Cell Biol 2004, 5(1):33-44.

15. Huang ZL, Gao M, Li QY, Tao K, Xiao Q, Cao WX, Feng WL: Induction of apoptosis by directing oncogenic Bcr-Abl into the nucleus. Oncotarget 2013, 4(12):2249-2260.

16. Vigneri $P$, Wang JY: Induction of apoptosis in chronic myelogenous leukemia cells through nuclear entrapment of BCR-ABL tyrosine kinase. Nat Med 2001, 7(2):228-234.

17. Dixon AS, Kakar M, Schneider KM, Constance JE, Paullin BC, Lim CS: Controlling subcellular localization to alter function: Sending oncogenic Bcr-Abl to the nucleus causes apoptosis. $J$ Control Release 2009, 140(3):245-249.

18. Li Q, Huang Z, Gao M, Cao W, Xiao Q, Luo H, Feng W: Blockade of Y177 and Nuclear Translocation of Bcr-Abl Inhibits Proliferation and Promotes Apoptosis in Chronic Myeloid Leukemia Cells. Int J Mol Sci 2017, 18(3). 
19. Izaurralde E, Kutay U, von Kobbe C, Mattaj IW, Gorlich D: The asymmetric distribution of the constituents of the Ran system is essential for transport into and out of the nucleus. EMBO J 1997, 16(21):6535-6547.

20. Woessner DW, Eiring AM, Bruno BJ, Zabriskie MS, Reynolds KR, Miller GD, O'Hare T, Deininger MW, Lim CS: A coiled-coil mimetic intercepts BCR-ABL1 dimerization in native and kinase-mutant chronic myeloid leukemia. Leukemia 2015, 29(8):1668-1675.

21. Lazenby M, Hills R, Burnett AK, Zabkiewicz J: The HSP90 inhibitor ganetespib: A potential effective agent for Acute Myeloid Leukemia in combination with cytarabine. Leuk Res 2015, 39(6):617-624.

22. Goetz MP, Toft DO, Ames MM, Erlichman C: The Hsp90 chaperone complex as a novel target for cancer therapy. Ann Oncol 2003, 14(8):1169-1176.

23. Khajapeer KV, Baskaran R: Hsp90 Inhibitors for the Treatment of Chronic Myeloid Leukemia. Leuk Res Treatment 2015, 2015:757694.

24. Wang Z, Hu Y, Xiao D, Wang J, Liu C, Xu Y, Shi X, Jiang P, Huang L, Li P et al: Stabilization of Notch1 by the Hsp90 Chaperone Is Crucial for T-Cell Leukemogenesis. Clin Cancer Res 2017, 23(14):38343846.

25. Bhatia S, Diedrich D, Frieg B, Ahlert H, Stein S, Bopp B, Lang F, Zang T, Kroger T, Ernst T et al: Targeting HSP90 dimerization via the $C$ terminus is effective in imatinib-resistant CML and lacks the heat shock response. Blood 2018, 132(3):307-320.

26. Nimmanapalli R, O'Bryan E, Bhalla K: Geldanamycin and its analogue 17-allylamino-17demethoxygeldanamycin lowers Bcr-Abl levels and induces apoptosis and differentiation of Bcr-Ablpositive human leukemic blasts. Cancer Res 2001, 61(5):1799-1804.

27. Peng C, Li D, Li S: Heat shock protein 90: a potential therapeutic target in leukemic progenitor and stem cells harboring mutant BCR-ABL resistant to kinase inhibitors. Cell Cycle 2007, 6(18):22272231.

28. Peiris MN, Meyer AN, Nelson KN, Bisom-Rapp EW, Donoghue DJ: Oncogenic fusion protein BCRFGFR1 requires BCR-mediated oligomerization and chaperonin Hsp90 for activation. Haematologica 2019.

29. Haque A, Alam Q, Alam MZ, Azhar El, Sait KH, Anfinan N, Mushtaq G, Kamal MA, Rasool M: Current Understanding of HSP90 as a Novel Therapeutic Target: An Emerging Approach for the Treatment of Cancer. Curr Pharm Des 2016, 22(20):2947-2959.

30. Calderwood SK: Heat shock proteins and cancer: intracellular chaperones or extracellular signalling ligands? Philos Trans R Soc Lond B Biol Sci 2018, 373(1738).

31. Blacklock K, Verkhivker GM: Experimentally guided structural modeling and dynamics analysis of Hsp90-p53 interactions: allosteric regulation of the Hsp90 chaperone by a client protein. J Chem Inf Model 2013, 53(11):2962-2978.

32. Qin JH, Wang K, Fu XL, Zhou PJ, Liu Z, Xu DD, Wang YF, Yang DP, Xie QL, Liu QY: Hsp90 inhibitor induces KG-1a cell differentiation and apoptosis via Akt/NF-kappaB signaling. Oncol Rep 2017, 38(3):1517-1524. 
33. Terry LJ, Shows EB, Wente SR: Crossing the nuclear envelope: hierarchical regulation of nucleocytoplasmic transport. Science 2007, 318(5855):1412-1416.

34. Thottassery JV, Westbrook L, Someya H, Parker WB: c-Abl-independent p73 stabilization during gemcitabine- or 4'-thio-beta-D-arabinofuranosylcytosine-induced apoptosis in wild-type and p53-null colorectal cancer cells. Mol Cancer Ther 2006, 5(2):400-410.

35. O'Brien SG, Deininger MW: Imatinib in patients with newly diagnosed chronic-phase chronic myeloid leukemia. Semin Hemato/ 2003, 40(2 Suppl 2):26-30.

36. Hughes TP, Mauro MJ, Cortes JE, Minami H, Rea D, DeAngelo DJ, Breccia M, Goh YT, Talpaz M, Hochhaus A et al: Asciminib in Chronic Myeloid Leukemia after ABL Kinase Inhibitor Failure. N Eng/ J Med 2019, 381(24):2315-2326.

37. Lee CF, Griffiths S, Rodriguez-Suarez E, Pierce A, Unwin RD, Jaworska E, Evans CA, S JG, Whetton AD: Assessment of downstream effectors of BCR/ABL protein tyrosine kinase using combined proteomic approaches. Proteomics 2010, 10(18):3321-3342.

38. Mancini M, Veljkovic N, Corradi V, Zuffa E, Corrado P, Pagnotta E, Martinelli G, Barbieri E, Santucci MA: 14-3-3 ligand prevents nuclear import of c-ABL protein in chronic myeloid leukemia. Traffic 2009, 10(6):637-647.

39. Wang H, Deng G, Ai M, Xu Z, Mou T, Yu J, Liu H, Wang S, Li G: Hsp90ab1 stabilizes LRP5 to promote epithelial-mesenchymal transition via activating of AKT and Wnt/beta-catenin signaling pathways in gastric cancer progression. Oncogene 2019, 38(9):1489-1507.

40. Piredda ML, Gaur G, Catalano G, Divona M, Banella C, Travaglini S, Puzzangara MC, Voso MT, LoCoco F, Noguera NI: PML/RARA inhibits expression of HSP90 and its target AKT. Br J Haematol 2019, 184(6):937-948.

41. Lee J, An YS, Kim MR, Kim YA, Lee JK, Hwang CS, Chung E, Park IC, Yi JY: Heat Shock Protein 90 Regulates Subcellular Localization of Smads in Mv1Lu Cells. J Cell Biochem 2016, 117(1):230-238.

42. Trepel J, Mollapour M, Giaccone G, Neckers L: Targeting the dynamic HSP90 complex in cancer. Nat Rev Cancer 2010, 10(8):537-549.

43. Butler LM, Ferraldeschi R, Armstrong HK, Centenera MM, Workman P: Maximizing the Therapeutic Potential of HSP90 Inhibitors. Mol Cancer Res 2015, 13(11):1445-1451.

44. Yuno A, Lee MJ, Lee S, Tomita Y, Rekhtman D, Moore B, Trepel JB: Clinical Evaluation and Biomarker Profiling of Hsp90 Inhibitors. Methods Mol Biol 2018, 1709:423-441.

45. Pan C, Chun J, Li D, Boese AC, Li J, Kang J, Umano A, Jiang Y, Song L, Magliocca KR et al: Hsp90B enhances MAST1-mediated cisplatin resistance by protecting MAST1 from proteosomal degradation. J Clin Invest 2019, 129(10):4110-4123.

46. Wang M, Shen A, Zhang C, Song Z, Ai J, Liu H, Sun L, Ding J, Geng M, Zhang A: Development of Heat Shock Protein (Hsp90) Inhibitors To Combat Resistance to Tyrosine Kinase Inhibitors through Hsp90Kinase Interactions. J Med Chem 2016, 59(12):5563-5586.

\section{Figures}


A

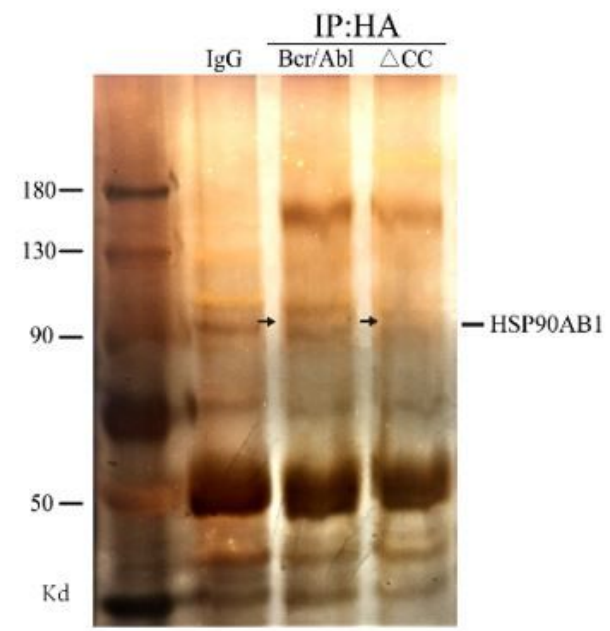

B

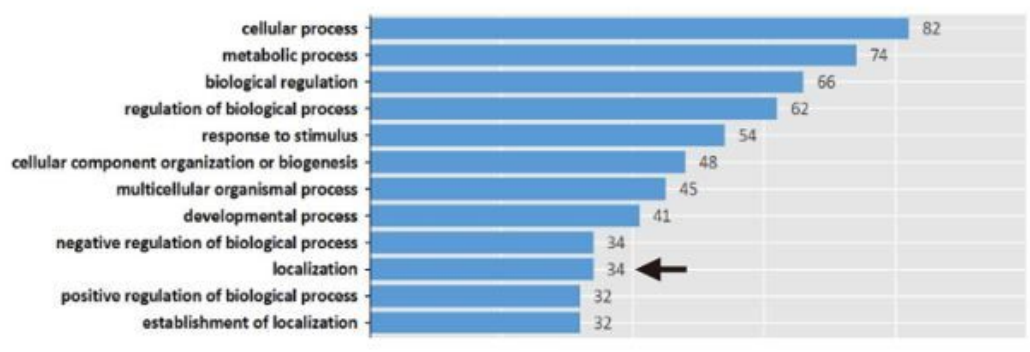

Gene Ontology_Cellular Component

C

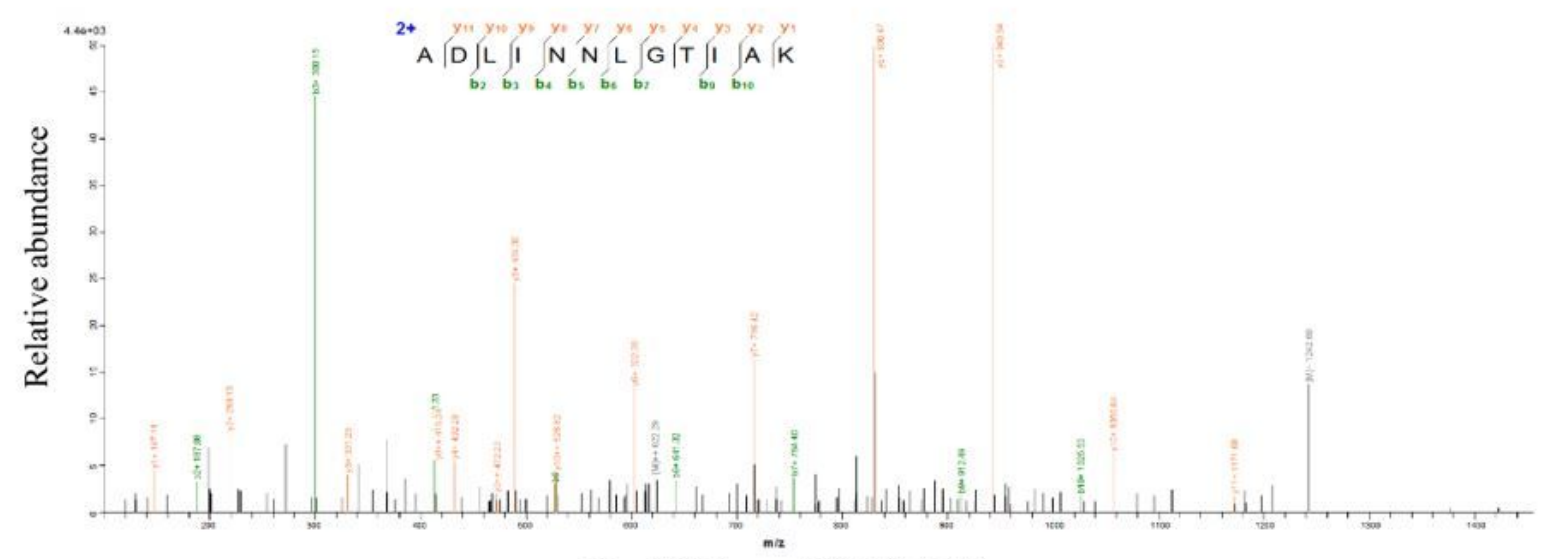

Hsp90B (gene HSP90AB1)

\section{Figure 1}

Identification of HSP90AB1 as a Bcr/Abl binding partner. (A) Total cell extracts prepared from 293T cells expressing $\mathrm{HA}$-tagged $\mathrm{Bcr} / \mathrm{Abl}$, $\mathrm{HA}$-tagged $\mathrm{Bcr} / \mathrm{Abl}-\triangle \mathrm{CC}$ or vector alone were subjected to immunoprecipitation using anti-HA beads. Proteins were resolved by SDS-PAGE and visualized by silver staining. (B) The proteins selected by LC/MS-MS were classified according to their related functions, and the differential proteins related to protein subcellular localization were screened out through GO_CC. (C) LC/MS-MS spectrometry of the purified HA-Bcr/Abl-associated peptides corresponding to HSP90AB1. 
A
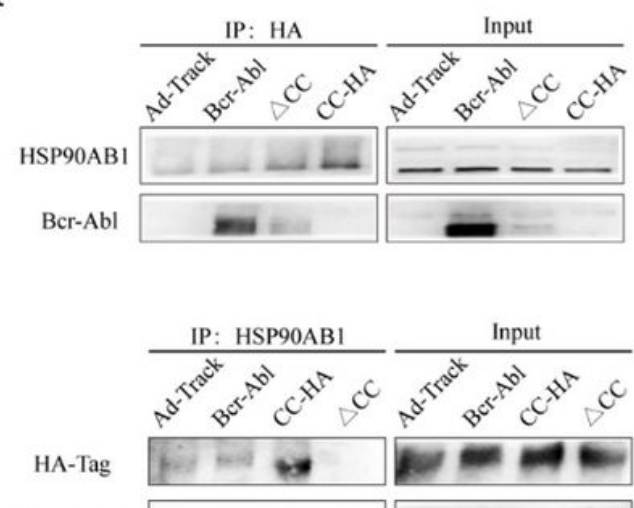

HSP90AB I

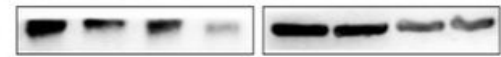

C

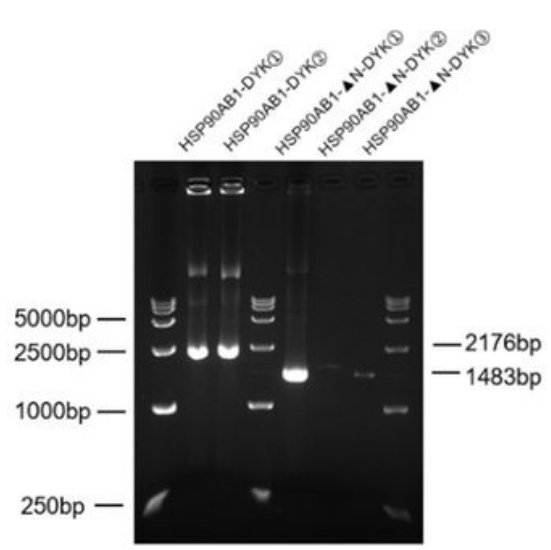

$\mathrm{E}$

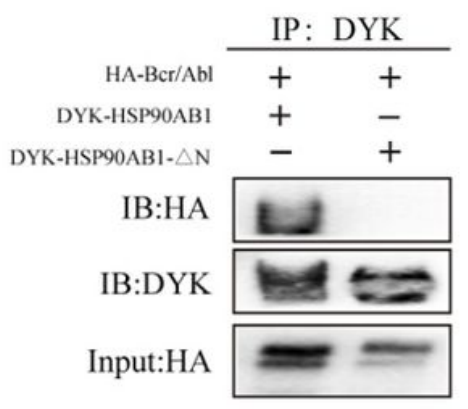

F

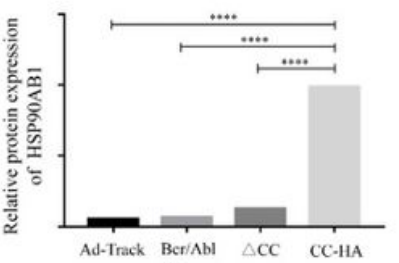

B

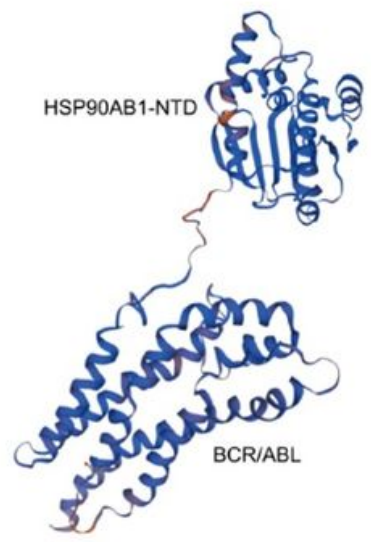

D

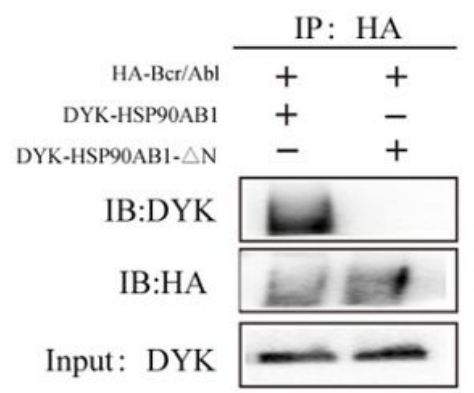

\section{Figure 2}

Association between the Bcr/Abl CC-domain and N-terminal domain of HSP90AB1. (A) DYK-tagged HSP90AB1 and/or HA-tagged Bcr-Abl were overexpressed in 293T cells and subjected to reciprocal coimmunoprecipitation (Co-IP) to detect protein interaction between Bcr-Abl and HSP90AB1. ${ }^{*} p<0.05$ and ${ }^{\star \star *} \mathrm{p}<0.001$. (B) The three-dimensional structure diagram of Bcr/Abl-HSP90AB1 binding protein was simulated using the bioinformatics analysis software Deep Viewer. (C) The target gene expression vectors DYK-pAdTrack-HSP90AB1 and DYK-pAdTrack-HSP90AB1- $\triangle$ NTD were successfully constructed by using molecular cloning technology. The target genes HSP90AB1 and HSP90AB1- $\triangle$ NTD were amplified 
by PCR technology, and their bases were 2176bp and 1483bp. (D) Immunofluorescence was used to observe the transfection efficiency of the target vector with the fluorescent label in 293T cells at $6 \mathrm{~h}, 24 \mathrm{~h}$, and 48h. (E, F) 293T cells expressing HA-tagged Bcr-Abl, DYK tagged HSP90AB1 or DYK-HSP90AB1- $\triangle \mathrm{N}$ were subjected to coimmunoprecipitation using anti-Flag beads.

A

K562

K562/G01
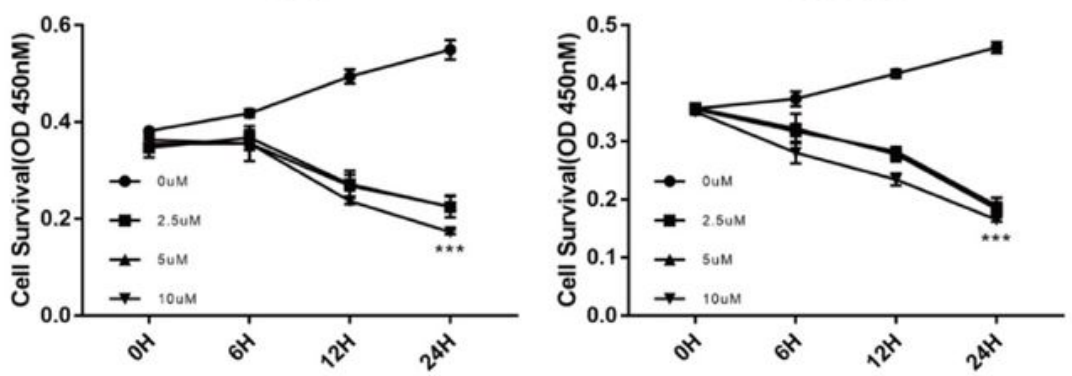

B

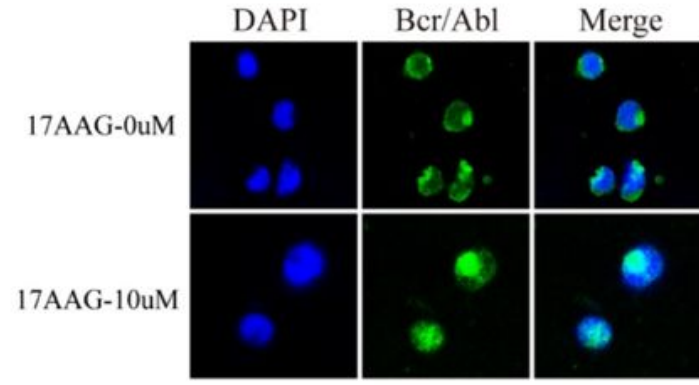

C

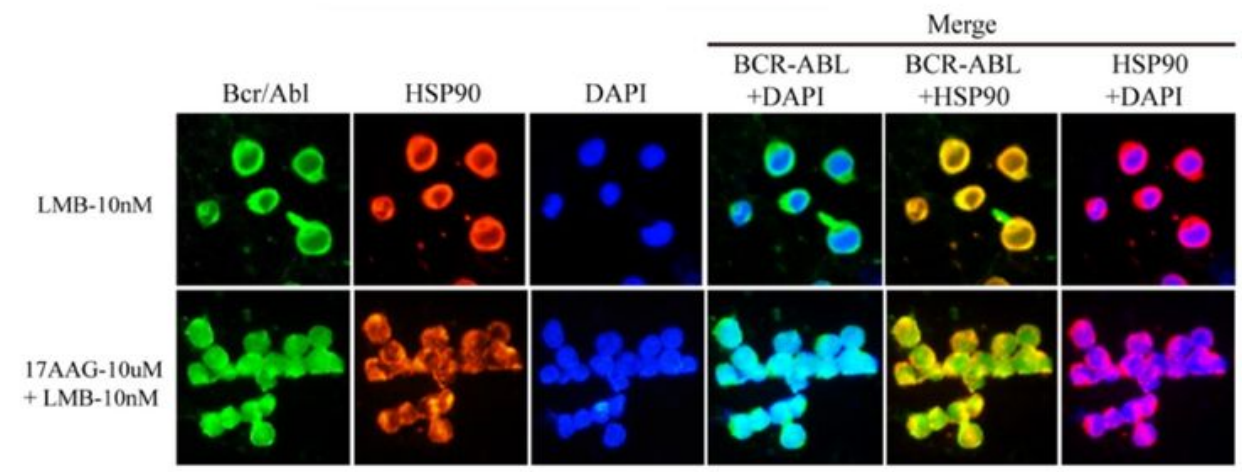

D

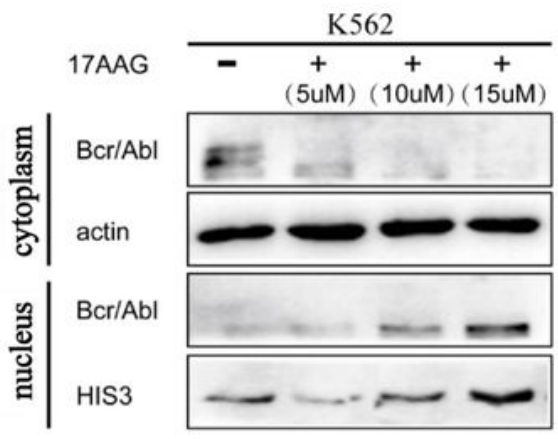

E

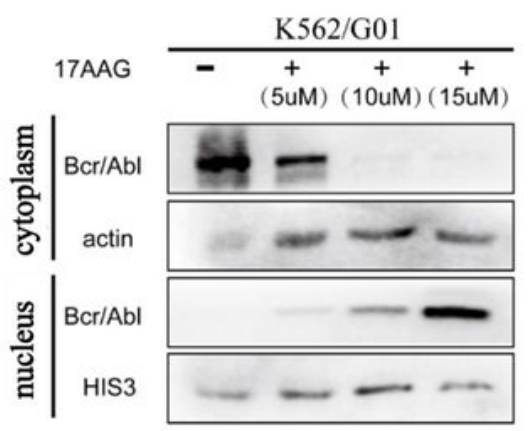

Figure 3 
Inhibition of HSP90AB1 induces nuclear localization of Bcr-Abl in CML cells. (A) The concentration of HSP90 inhibitor 17AAG on CML cells was screened by Cell Counting Kit-8 experiment. ${ }^{\star} p<0.05$, ${ }^{\star \star} p<$ 0.01 and ${ }^{* \star} \mathrm{p}<0.001$. (B) The changes of Bcr-Abl localization in K562 cells treated with HSP90 inhibitor 17AAG were observed by indirect immunofluorescence. (C) The changes of Bcr-Abl localization in K562 cells treated with HSP90 inhibitor 17AAG and protein nuclear export inhibitor LMB were observed by indirect immunofluorescence. (D, E) The changes of Bcr-Abl protein expression in cytoplasm and nucleus of K562 and K562/G01 cells treated with HSP90 inhibitor 17AAG were observed by western blot analyses.

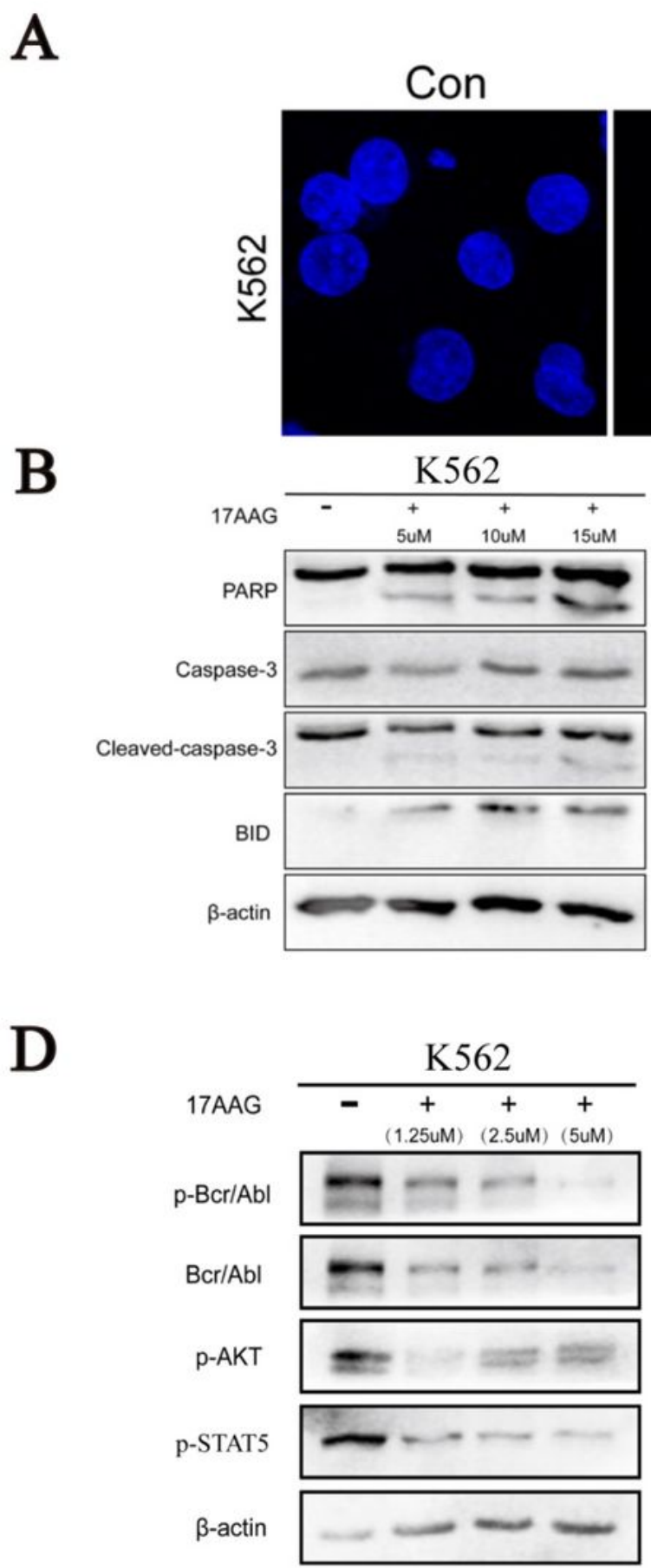

$6 \mathrm{H}$
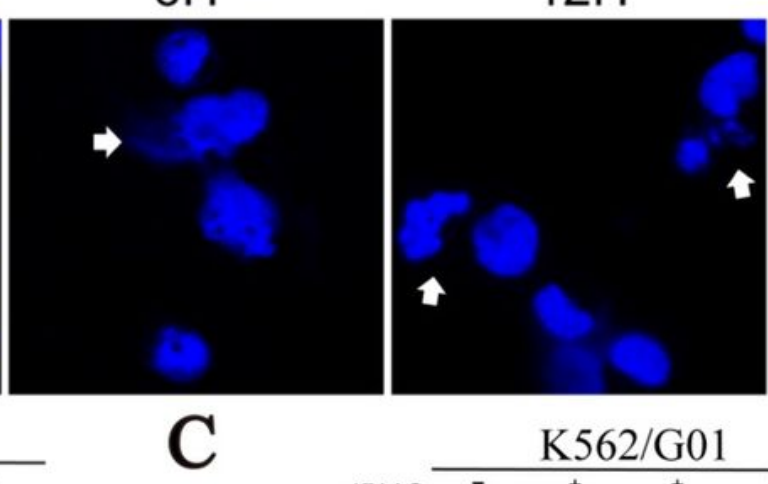

\section{$116 \mathrm{kDa}$} $89 \mathrm{kDa}$ $35 \mathrm{kDa}$ $19 \mathrm{kDa}$ $17 \mathrm{kDa}$ $15 \mathrm{kDa}$ $43 \mathrm{kDa}$

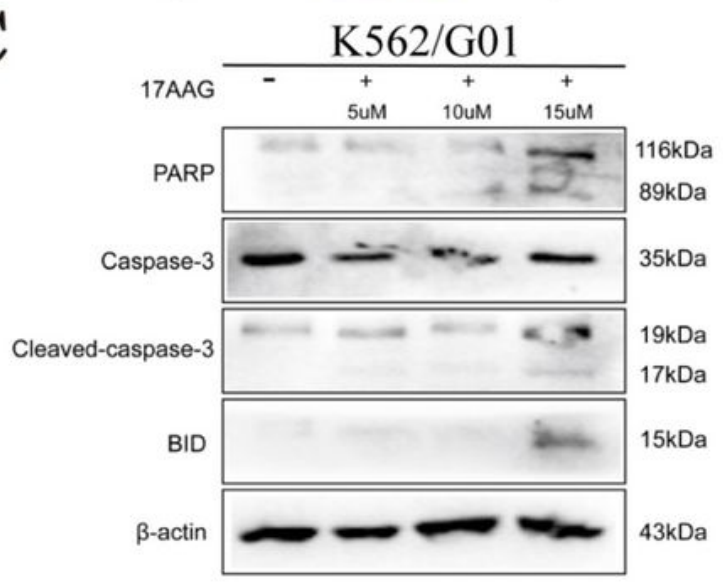

E

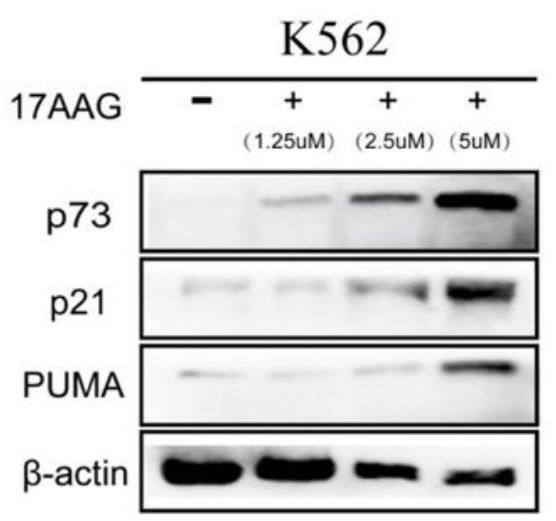




\section{Figure 4}

Nuclear transport of Bcr-Abl induced apoptosis in K562 and K562/G01 cells through Bcr-Abl kinasedependent and Bcr/Abl-independent pathways. (A) The nuclear morphological structure changes of K562 cells were observed by DAPI fluorescence staining after being treated with 17AAG $(10 \mu \mathrm{M})$ for $6 \mathrm{hrs}$, and 12 hrs. (B, C) To observe the effect of Bcr-Abl on the activation of apoptosis-related proteins in $\mathrm{K} 562$ and K562/G01 cells by western blot analyses. (D) The effect of HSP90 inhibitor 17AAG on the activation of $\mathrm{Bcr-Abl,} \mathrm{p-Bcr/Abl} \mathrm{and} \mathrm{downstream} \mathrm{signaling} \mathrm{molecules} \mathrm{such} \mathrm{as} \mathrm{p-AKT} \mathrm{and} \mathrm{p-STAT5} \mathrm{in} \mathrm{K562} \mathrm{cells.} \mathrm{(E)}$ The effect of HSP90 inhibitor 17AAG on the activation of p73 and downstream signaling molecules such as $\mathrm{p} 21$ and PUMA in K562 cells. 
A

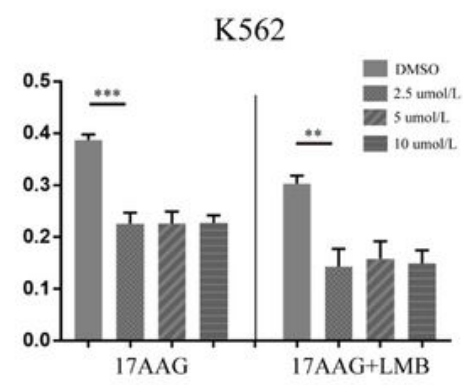

C

D

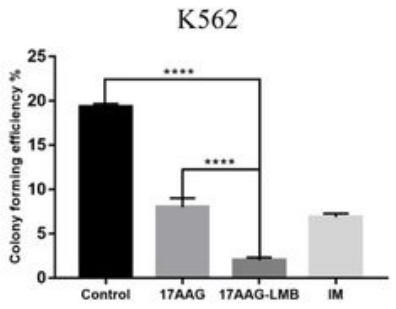

B

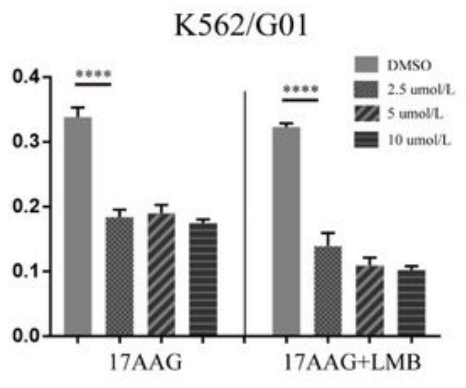

17AAG-LMB IM
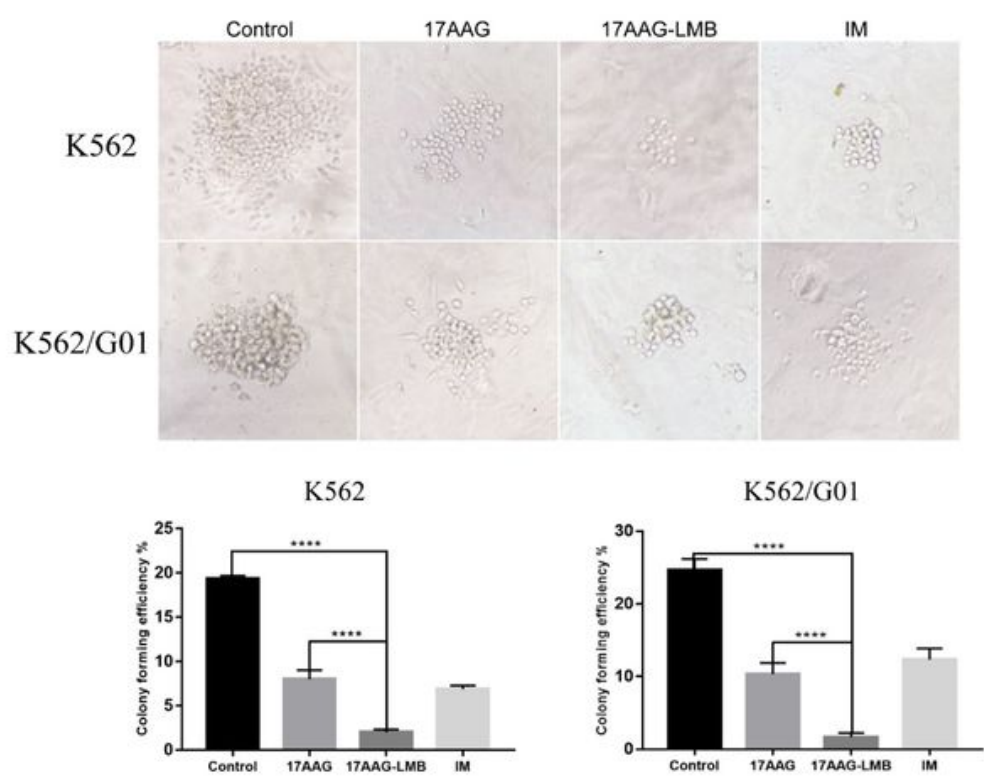

$\mathrm{E}$

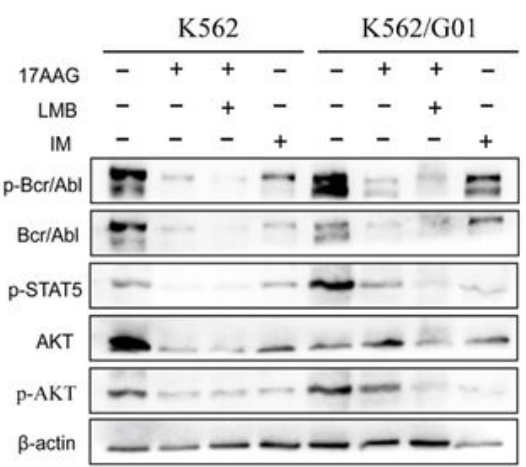

Figure 5

Combinational therapy of 17AAG and LMB significantly inhibits the malignant proliferation of CML cells. $(A, B)$ CCK-8 assay compared the effects of 17AAG with the effects of 17AAG combined with LMB on the proliferation of K562 and K562/G01 cells. (C, D) To observe the effect of drug combination on cell proliferation ability in clone formation experiments and count the number of colonies after being treated with $10 \mu \mathrm{M}$ 17AAG combined with $10 \mathrm{nM}$ LMB for 5 days. (E) Effects of activation of Bcr-Abl and 
downstream signaling molecules in K562 and K562/G01 cells were associated with the use of $10 \mu \mathrm{M}$ 17AAG combined with $10 \mathrm{nM}$ LMB. ${ }^{\star} \mathrm{p}<0.05,{ }^{*} \mathrm{p}<0.01$ and ${ }^{* *} \mathrm{p}<0.001$.

A

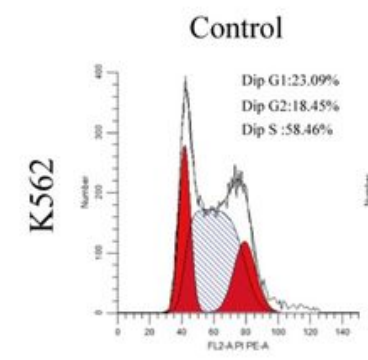

17AAG

17AAG-LMB

IM
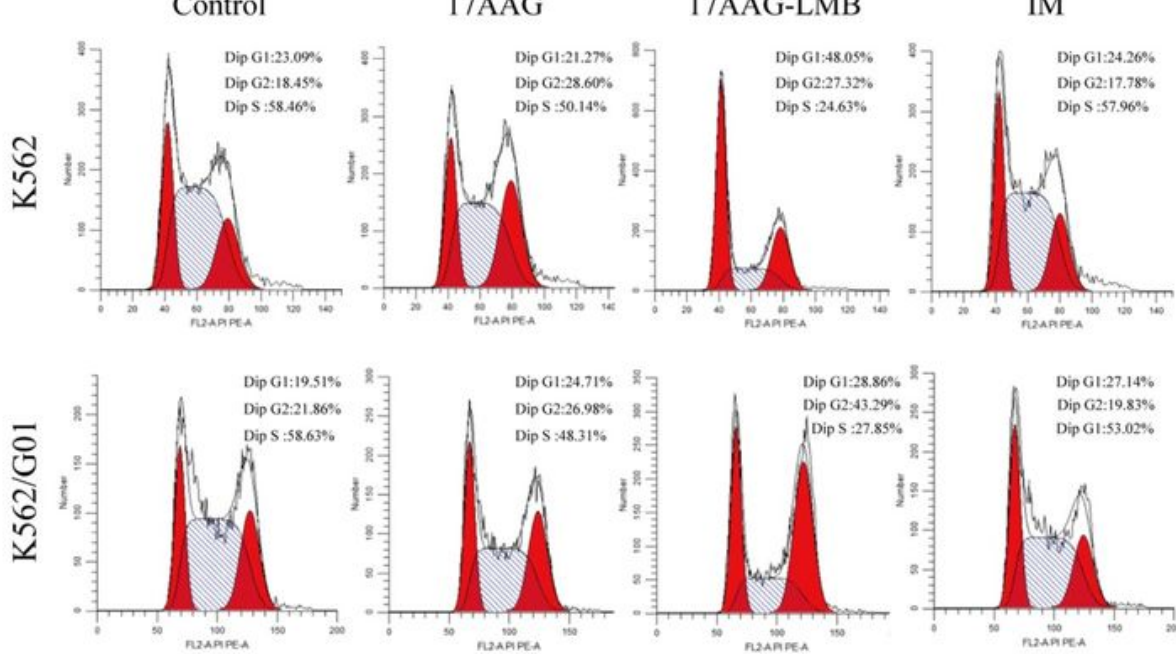

B
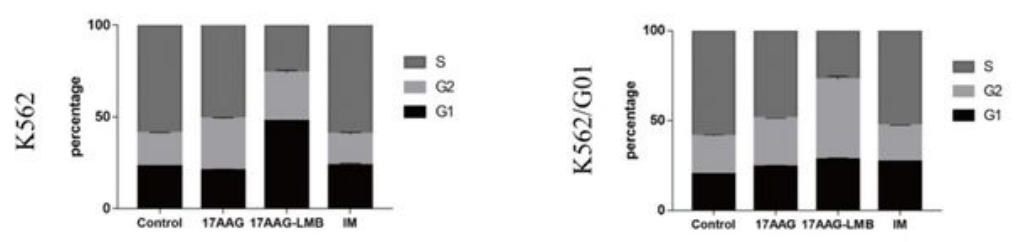

C
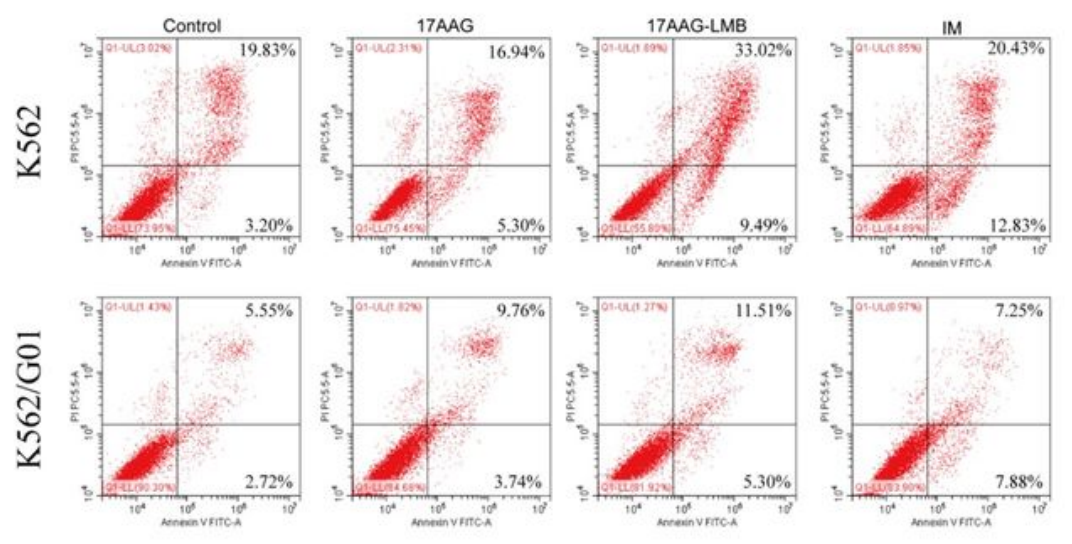

D
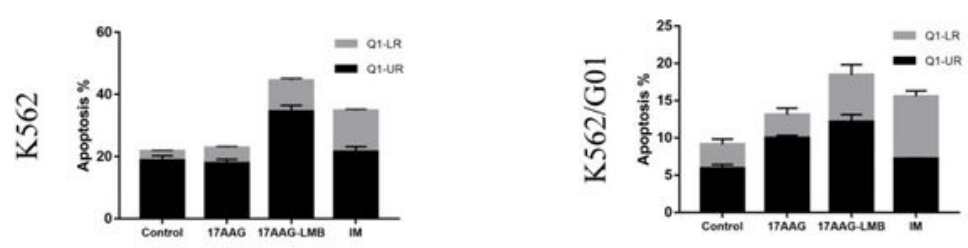

Figure 6

HSP90 inhibitor 17AAG combined with protein nucleus export inhibitor LMB could enhance the killing ability when targeting CML cells. After being treated with 10 $\mu \mathrm{M}$ 17AAG for $6 \mathrm{hrs}, 2 \mu \mathrm{M}$ IM for $24 \mathrm{hrs}$ or $10 \mu \mathrm{M}$ 17AAG combined with 10nM LMB for 6 hrs. (A, B) Flow cytometry cycle analysis of K562 and 
K562/G01. (C, D) Flow cytometry apoptosis analysis of K562 and K562/G01 suggested that the malignant proliferation capacity of $\mathrm{CML}$ cells was significantly reduced with the drug combination treatment, and the drugs combination treatment could enhance the ability of promoting apoptosis of CML cells.

A

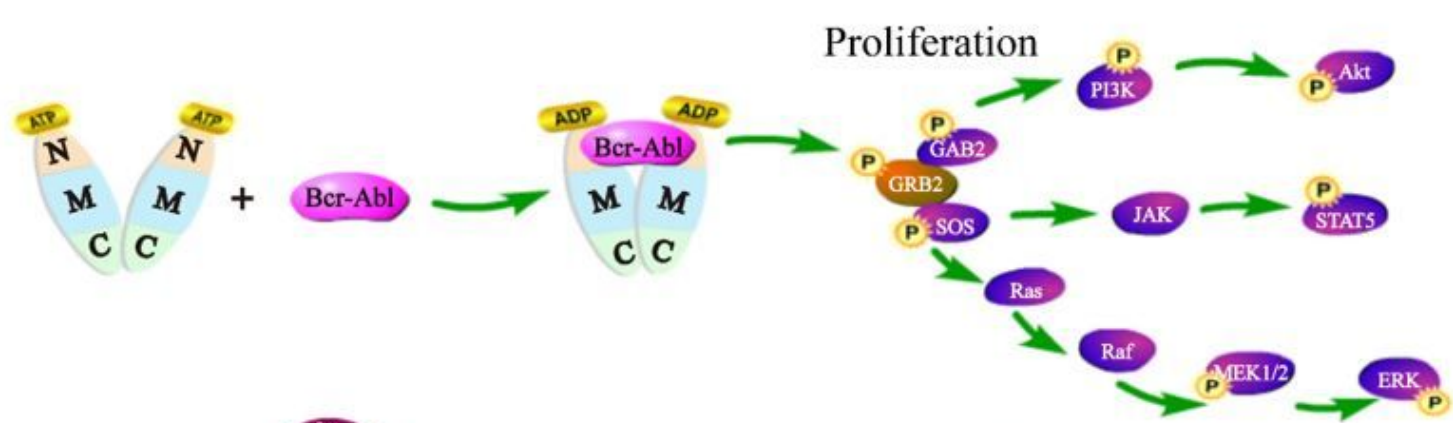

B
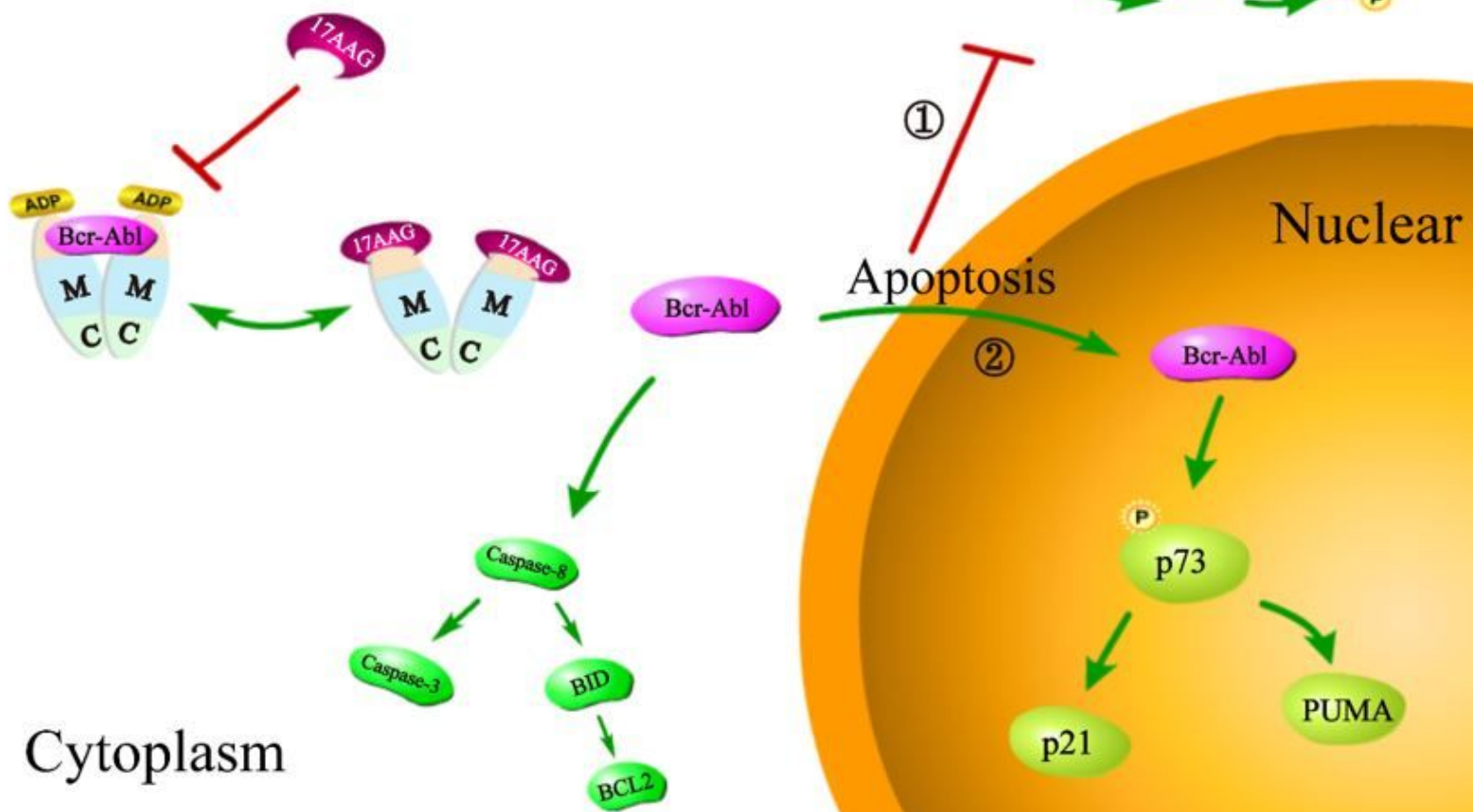

\section{Figure 7}

Work model of transporting Bcr-Abl to the nucleus: (A) Normally, Bcr-Abl locates in the cytoplasm and its high tyrosine kinase activity activates multiple downstream signaling pathways, such as JAK/STAT, $\mathrm{PI} 3 \mathrm{~K} / \mathrm{AKT}$, and RAS/MAPK; (B) When Bcr-Abl is transported into the nucleus under the influence of 17AAG, the specificity binding between 17AAG and HSP90AB1 inhibited the cytoplasmic malignant proliferation signaling though competitively blocking the formation of Bcr/Abl-HSP90AB1 complex; the nucleus-entrapped Bcr-Abl activated p73 and induced the apoptosis of CML cells.

\section{Supplementary Files}

This is a list of supplementary files associated with this preprint. Click to download. 
- 4.SupplementaryMaterial.docx

Page 23/23 